\title{
Histoire de Hongrie dans les relations historiques et culturelles
}

\author{
Etienne Boisserie (Paris)
}

Peter Kónya (ed.): Dejiny Uhorska (1000-1918). Prešov: Vydavatel'stvo Prešovskej univerzity v Prešove, 2013. 787 s. ISBN 978-80-555-0921-1.

Il s'agit de la première histoire globale consacrée exclusivement au royaume de Hongrie et couvrant l'ensemble de la période écrite par un collectif de chercheurs slovaques. Elle répond incontestablement à un manque persistant de l'historiographie slovaque jusqu'à présent. Même si son évolution est importante depuis quelques années, l'histoire de la Hongrie était encore abordée principalement par la période de la construction de la nation slovaque moderne et elle était encore très marquée thématiquement soit par ce qu'il est convenu d'appeler „národný útlak“, soit par l'analyse des évolutions des différentes composantes de la société patriotique ou par la „československá vzájomnost“". Or, les auteurs rappellent à juste titre cette évidence que „Dejiny Uhorska sú organickou súćastou minulosti Slovenska“ (s. 8) et qu'elle doit donc être abordé dans ce cadre d'analyse. Tout au long de l'ouvrage, les auteurs parviennent à conserver le format de leur objet - l'histoire du royaume - à y intégrer les phénomènes régionaux lorsque cela est nécessaire et à offrir ainsi une histoire tout à la fois extrêmement documentée et d'une grande lisibilité.

L'ouvrage est divisé en quatre grandes périodes: Karpatská kotlina pred vznikom Uhorska, Stredoveké Uhorsko (Vladimír Segeš), Uhorsko v ranom novoveku 1526-1790 (Peter Kónya), Vzostup a pád v dlhom storoči (Peter Kónya a Ivan Mrva). Chacune de ces parties est décomposée selon une chronologie d'histoire politique de facture classique. L'ensemble est remarquablement synthétique sur le plan thématique, d'une lecture aisée, équilibré et homogène dans l'importanceaccordée à chacune des périodes. La partie médiévaleembrasselargement les trans- formations de la relations royauté-noblesse, les évolutions internes et les rapports de force régionaux auxquels le royaume est confronté. L'histoire politique y occupe une place centrale, et on pourra regretter la que l'analyse des structures sociales et de leur évolution ou desphénomènes économiques et commerciauxse limite à une dernière sous-partie, certes riche, mais qu'on aurait aimé pouvoir connecter à des sous-périodes étudiées par ailleurs avec une grande précision.

La partie consacrée aurano novovek est découpée en trois sous-périodes classiques de l'historiographie hongroise (1526-1606; 16061699; 1699-1790). Elle prend en compte de manière détaillée la tripartition du royaume et les soulèvements hongrois ainsi que l'accroissement de la complexité religieuse et de ses implications politiques. La transformation des cadres mentaux et sociaux comme celle de la production ou des flux commerciaux sont étudiées avec grand soin, aussi bien dans une persepctive de longue durée en phase instable (16e et $17 \mathrm{e}$ siècles) que dans les phases charnières. À ce titre, l'attention accordée à la colonisation du royaume dans la première moitié du 18e siècle, mais plus largement aux grandes transformations induites par le recul ottoman et par la période paix intérieure inhabituellement longue est très utile. Ce contexte initial une fois clairement posé, l'absolutisme éclairé occupe à lui seul une sous-partie et les réformes thérésiennes et joséphiennes sont observées dans leur contexte immédiat comme dans leurs conséquences à moyen terme. La place substantielle qui leur est accordée rappelle leur importance structurelle. 
Le dernier chapitre, consacré au „long xixe siècle“ adopte comme les partie précédentes une chronologie classique dans une perspective d'histoire hongroise (1790-1848, 18481867, 1867-1918). Il développe avec méthode le contexte, les processus et les acteurs de la construction de la nation hongroise moderne abordée dans le contexte plus large des transformations sociales et nationales du Vormärz. À ce stade, l'histoire sociale, culturelle et intellectuelle est éclairée avec une particulière attention et resituée dans le cadre impérial qui lui sert de toile de fond. Cette importance accordée aux fondements de la conception moderne de la nation hongroise permet d'expliciter la dynamique et la cohérence interne de cette doctrine et familiarise le lecteur aux clivages qui structureront le royaume dans la seconde moitié du siècle. La période 1848-1867 est abordée sous la forme d'un récit classique, précis et primordialement politique qui couvre les différentes phases révolutionnaires, l'absolutisme de Bach et les stratégies des libéraux hongrois après la chute de ce dernier. La période du Compromis en tant que tel ouvre plus encore que les chapitres précédents aux grandes transformations sociales et économiques que les auteurs font précéder d'un chapitre d'histoire politique précis. Le lecteur dispose ainsi d'un tableau nuancé et factuellement précis, équilibré dans son approche et qui s'efforce avec succès de ne pas faire prévaloir certaines dimensions souvent écrasantes dans l'approche de cette période
- on pense ici en particulier à la question des nationalités.

Dans ce dernier chapitre comme dans les précédents, les auteurs tiennent remarquablement bien leur objectif d'offrir une synthèse de vulgarisation exigeante, ils ont le souci de la pondération des différentes composantes abordées, d'identifier et de problématiser les processus qu'ils observent. À plusieurs égards, cet ouvrage peut être considéré comme un travail fondamental indispensable à l'étude de l'histoire slovaque et qui, par sa vocation globale, comble un manque sous cette forme.

On ne peut qu'être en accord sur le postulat des auteurs pour lesquels „či sa to niekomu páči alebo nie, tieto stáročia výrazne ovplyunili (nielen slovenskú) národnú mentalitu, myslenie, naturel a kultúru v najširšom zmysle slova, pričom v súčasnosti sa denne okolo seba stretávame s uhorským dedičstvom v najrozličnejšich podobách". Dans ce sens, la réintégration de l'histoire slovaque - qui n'apparaît ici que discrètement - dans sa dimension régionale d'un ensemble plus vaste est un travail utile et qui permet d'ouvrir la focale. Les auteurs parviennent à tenir leur postulat. En exposant la complexité de l'ensemble uhorský dans ses différentes dimensions politiques, géostratégiques, sociales, économiques et culturelles, ils éclairent d'une autre lumière les phénomènes propres à l'espace slovaque que cet ensemble imprègne.

E-mail: eboisserie@gmail.com 